\title{
Blood Cholesterol Level and Risk of Stroke in Community-based or Worksite Cohort Studies: A Review of Japanese Cohort Studies in the Past 20 years
}

\author{
Taichiro Tanaka ${ }^{1}$ and Tomonori Okamura ${ }^{2}$ \\ ${ }^{1}$ Department of Health Sciences, Interdisciplinary Graduate School of Medicine and Engineering, \\ University of Yamanashi, Yamanashi, Japan \\ ${ }^{2}$ Department of Preventive Medicine and Public Health, School of Medicine, Keio University, Tokyo, Japan
}

(Received for publication on September 5, 2011)

(Revised for publication on October 26, 2011)

(Accepted for publication on November 17, 2011)

\begin{abstract}
Evidence of the causal relationship between hypercholesterolemia and coronary artery disease (CAD) has been established worldwide. However, little attention has been paid to the relationship between hypercholesterolemia and stroke, despite stroke being the most common cardiovascular disease in Japan. We therefore reviewed cohort studies that investigated this relationship in the Japanese population over the past 20 years, and compared their findings with clinical trials and cohort studies in Western countries. Fourteen cohort studies were carried out in Japan during this period. The number of subjects in the studies ranged from 1621 to 91,219 and the mean follow-up period ranged from 7.6 to 32 years. The majority of studies showed no association between hypercholesterolemia and total stroke. However, one report showed a positive association between low-density lipoprotein cholesterol and atherothrombotic cerebral infarction. The relationship between hypercholesterolemia and cerebral infarction may be modified by the proportion of atherothrombotic infarctions in the population surveyed. Randomized controlled trials on statins have shown a substantial reduction in cerebral infarction, and so the discrepancy between cohort studies and clinical trials requires further study. However, some studies have reported that subjects with low blood cholesterol are more susceptible to intracerebral hemorrhage. Two hypotheses have been proposed to explain this association between low cholesterol and intracerebral hemorrhage. First, low blood cholesterol may induce angionecrosis, possibly in combination with hypertension, and second, low blood cholesterol may reflect a poor nutritional status. Either way, further continuous research in various fields of medical science is required to clarify the overall effect of blood cholesterol on stroke in humans. (Keio J Med 61 (3) : 79-88, September 2012)
\end{abstract}

Keywords: cholesterol, stroke, cohort studies, cerebral infarction, intracerebral hemorrhage

\section{Introduction}

The causal relationship between coronary artery disease (CAD) and high serum levels of total cholesterol (TC) or low-density lipoprotein cholesterol (LDLC) is well established. ${ }^{1-4}$ Serum cholesterol levels are therefore the main target for lipid management and prevention of atherosclerotic disease in the guidelines of the major- ity developed countries. Furthermore, some U.S. cohort studies have suggested that non-high-density lipoprotein cholesterol (non-HDLC) may be a better predictor of CAD. ${ }^{5,6}$ Non-HDLC reflects the total cholesterol concentration of all atherogenic lipoproteins and is calculated by subtracting the level of high-density lipoprotein cholesterol (HDLC) from that of TC. The Health and Medical Service Law for the Elderly was enacted in 1982, and as

Reprint requests to: Tomonori Okamura, MD, PhD, Department of Preventive Medicine and Public Health, School of Medicine, Keio University, 35 Shinanomachi, Shinjuku-ku, Tokyo 160-8582, Japan, E-mail: okamura@z6.keio.jp

Copyright (C) 2012 by The Keio Journal of Medicine 
a result, all Japanese citizens aged 40 years and over have had the opportunity to undergo screening for TC from 1986 and screening for HDLC from 1992. Citizens with dyslipidemia are also provided with health services such as health education to prevent CAD. For this screening system, the basis was changed from TC to LDLC in April 2008.

In contrast, little attention has been paid to the relationship between hypercholesterolemia and stroke, despite stroke being the most common cardiovascular disease in Japan. ${ }^{7}$ There is evidence that the mean cholesterol level in the Japanese population has been lower than that in most Western countries for many decades and this is associated with a lower CAD mortality than in Western populations. ${ }^{7}$ However, to clarify the relationship between hypercholesterolemia and stroke it is necessary to carry out original cohort studies. This review article focuses on a series of cohort studies performed in Japanese community-based or worksite populations. These studies provide evidence that partially establishes the long-held, but unconfirmed, belief that hypercholesterolemia is associated with stroke.

\section{Overview of Japanese Cohort Studies Carried Out in the Past Two Decades}

We performed a PubMed literature search of studies published between January 1991 and August 2011. We used the search terms "cholesterol" in combination with "cerebrovascular disease or stroke," "Japan or Japanese" and "cohort studies." Studies were selected using the following criteria: (1) reports were published in English, (2) studies were performed in Japan, (3) studies were of the prospective cohort type (including nested case-control studies), and (4) statistical analyses were carried out on the relationship between cholesterol levels (TC, LDLC, non-HDLC) and stroke endpoint (fatal and/or non-fatal stroke including its subtypes) adjusted at least for age and hypertension (including blood pressure levels). Finally, we selected potentially relevant articles based on the title and the abstract, and obtained the full text of these articles for detailed review.

Table 1 summarizes the cohort studies carried out on Japanese populations over the past 20 years, listed in chronological order of date of publication. Of the 14 studies, ${ }^{8-21} 2$ studies were on worksite populations ${ }^{8,18}$ and the remaining 12 studies were on residents of various communities. All but one of the studies were cohort studies, the exception being a nested case-control study. ${ }^{13}$ The number of subjects ranged from 1621 to 91,219 , and the mean or median follow-up periods ranged from 7.6 to 32 years. In the cohort studies, the endpoint in eight studies was the first occurrence of stroke and/or its subtypes during the follow-up period, ${ }^{8-10,14-16,18,19}$ and in six studies, the endpoint was death due to stroke and/or its subtypes. ${ }^{11-13,17,20,21}$ Apart from two studies, ${ }^{10.16}$ all the investigations also examined the relationship between TC (or LDLC or non-HDLC) and myocardial infarction (MI) or CAD. A positive association between hypercholesterolemia and CAD was shown in all but two of the studies $^{20,21}$ (data not shown in the table). In contrast, the majority of studies showed no association between hypercholesterolemia and total stroke events. Furthermore, some studies reported that community residents with low serum TC or LDLC levels were more likely to develop intracerebral hemorrhage..$^{1-13,17,21}$ Only one recent report from the Hisayama study showed a positive association between LDLC and atherothrombotic cerebral infarction. ${ }^{15}$ Several of the above-mentioned studies are discussed in more detail below.

\section{Summary of Key Studies}

\section{NIPPON DATA80}

The cohort studies of the National Survey on Circulatory Disorders, 1980, Japan, are referred to as NIPPON DATA80 (National Integrated Project for Prospective Observation of Non-communicable Disease and Its Trends in the Aged, 1980). ${ }^{11,12}$ The baseline surveys were performed in 1980. In 1980 approximately 10,000 community residents aged 30 years or older from 300 randomly selected districts participated in a survey. Figure 1 shows the relationship between TC and death due to CAD in the 17.3-year follow-up period of NIPPON DATA $80 .{ }^{12} \mathrm{~A}$ positive, graded relationship was observed between the two parameters in men. Although a graded relationship was not observed in women, the group with the highest $\mathrm{TC}$ had a significantly increased risk of death from CAD. In contrast, there was no association between TC and the risk of stroke mortality (Fig. 2). Limited analysis showed there was also no association between TC and death due to cerebral infarction. However, this study had some limitations. The first is the possible misclassification of stroke diagnosis because the endpoints were determined from death certificates. The second is that TC includes HDLC, a protective factor for atherosclerosis. These issues were therefore addressed by other cohort studies.

\section{The Suita study}

The Suita study was established in 1989 and invited 12,200 Japanese urban residents of Suita City, Osaka, to participate. The participants were 30-79 years old and were selected randomly from the municipal population registry. Of these, 6485 men and women took part in a baseline medical examination at the National Cardiovascular Center between September 1989 and February 1994. The endpoints of this study were the first incidence of MI or stroke. In this study, ${ }^{14}$ the relative risk for MI in the top quintile of LDLC $(\geq 151 \mathrm{mg} / \mathrm{dl}$ in men and $\geq 164 \mathrm{mg} / \mathrm{dl}$ in 


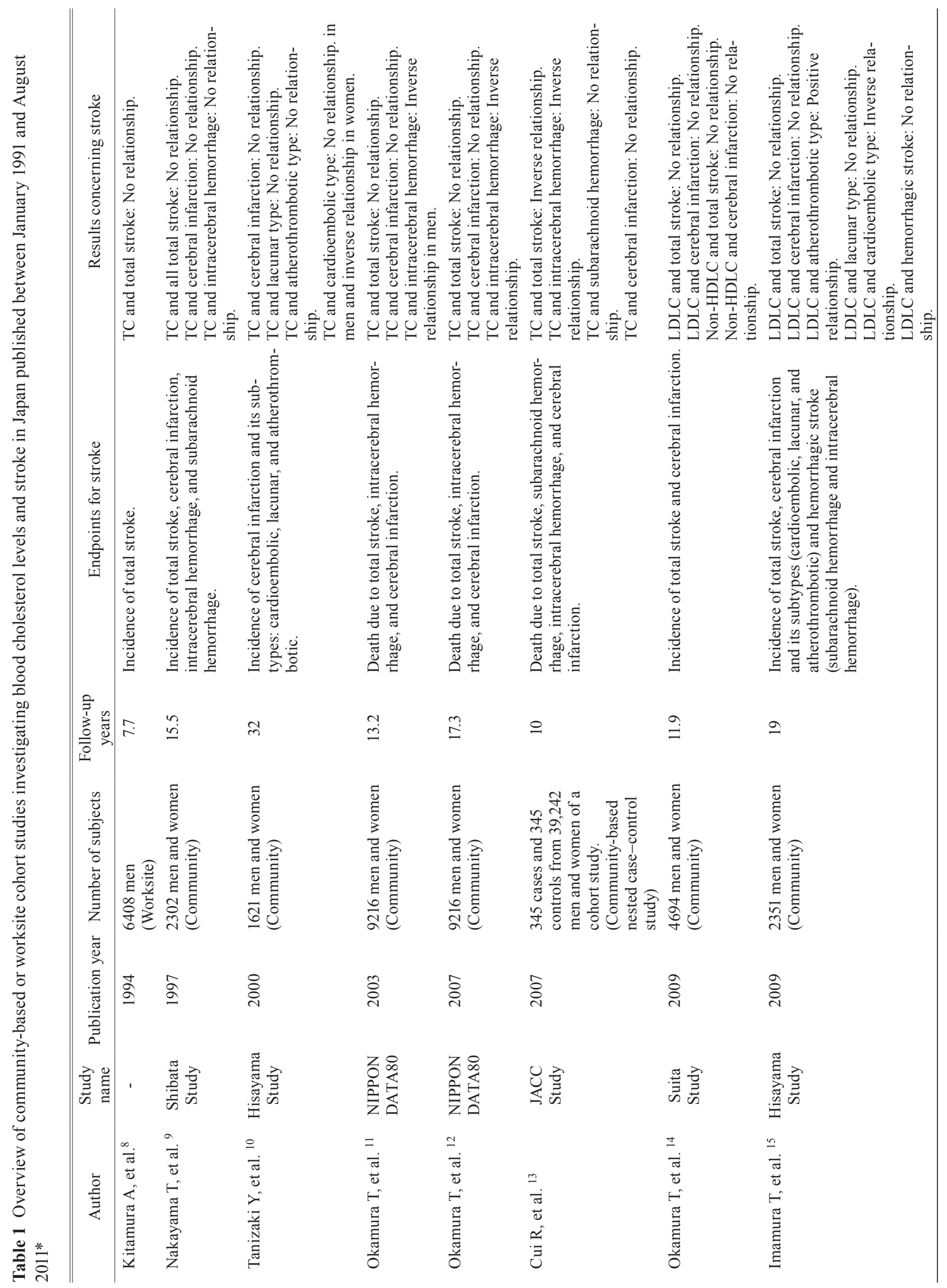




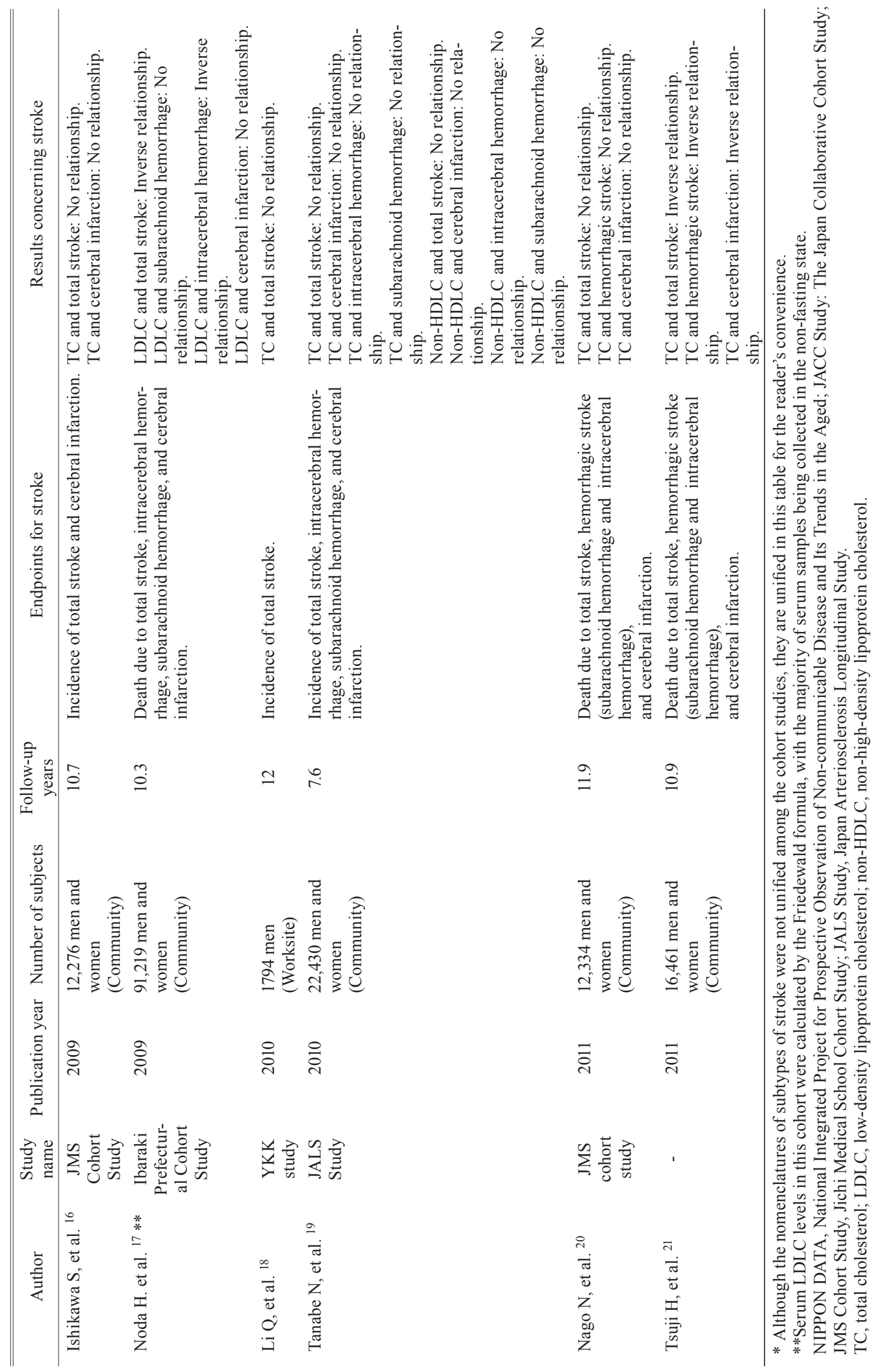




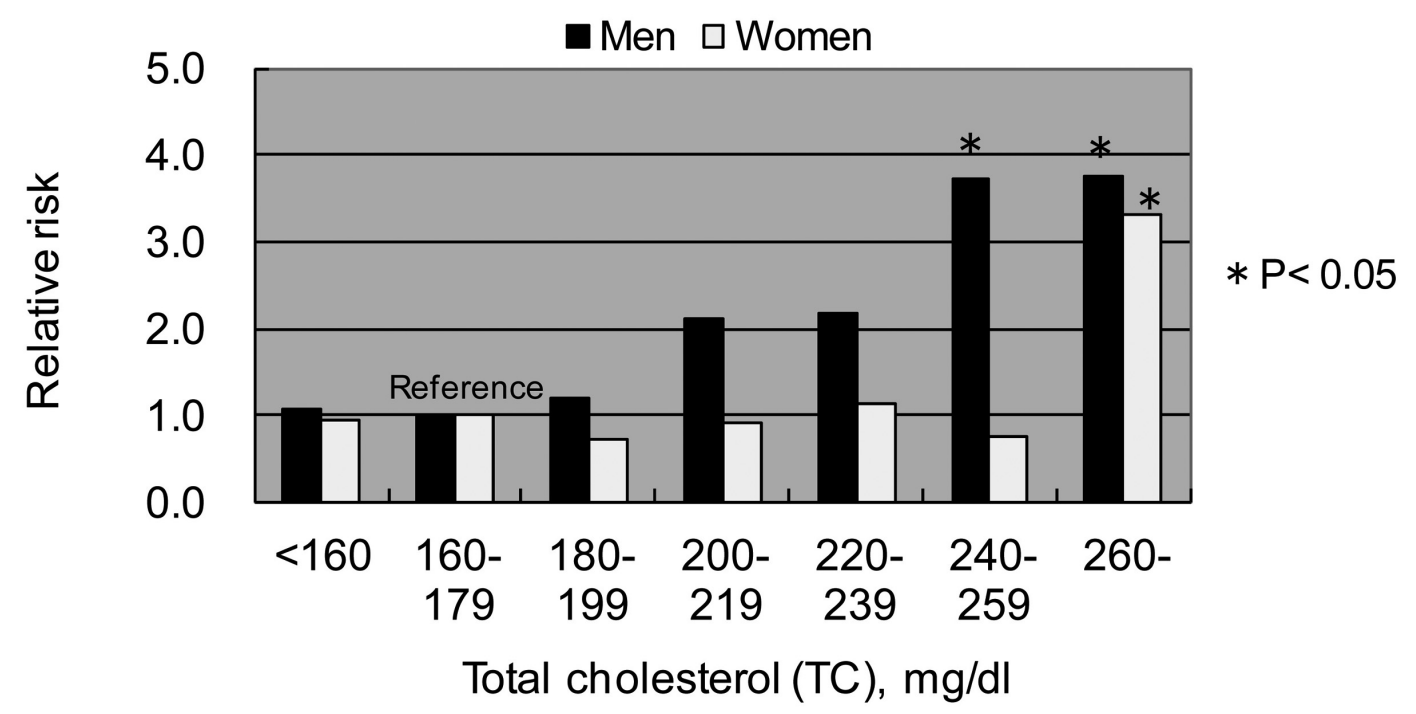

Fig. 1 Total cholesterol and coronary mortality data from NIPPON DATA80.

Multivariable-adjusted relative risk (RR) for coronary artery disease (CAD) mortality grouped according to serum total cholesterol (TC) after adjustment for age, serum albumin, body mass index, hypertension, diabetes, cigarette smoking, and alcohol intake. RR data are shown as black bars for men and white bars for women (from Okamura T, et al. ${ }^{12}$ ). ${ }^{*} \mathrm{P}<0.05$ vs. reference group.

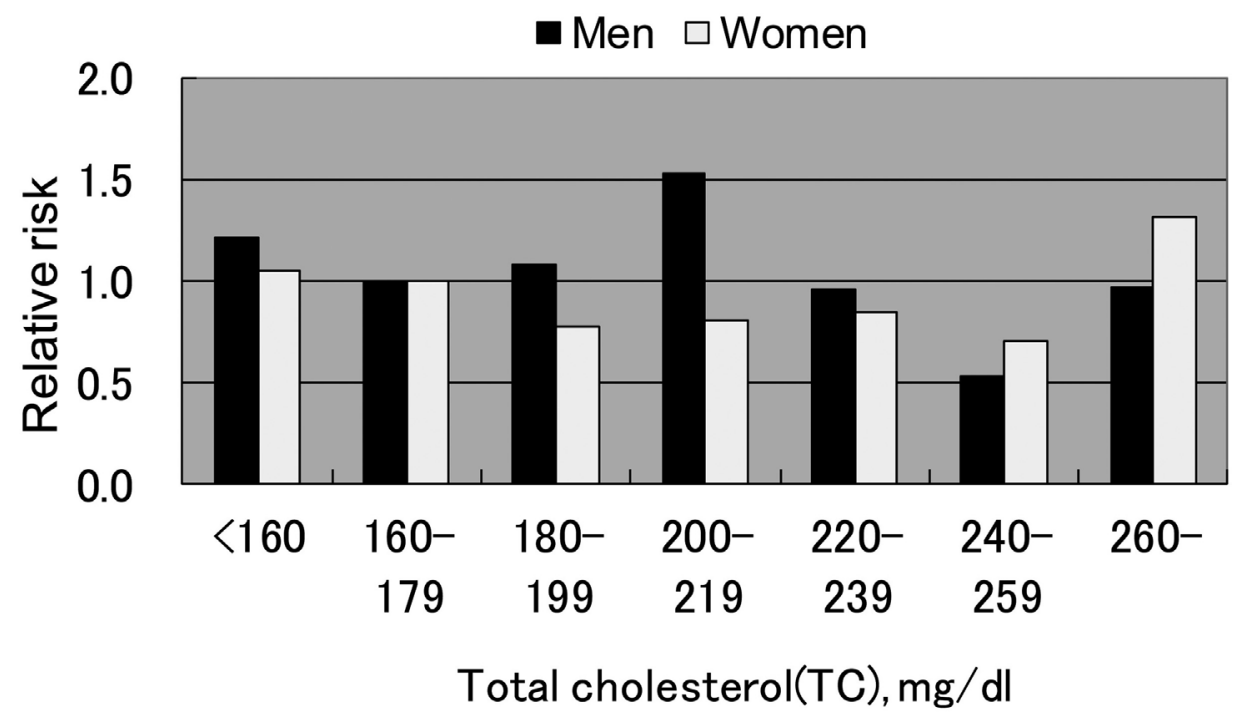

Fig. 2 Total cholesterol and stroke mortality data from NIPPON DATA80.

Multivariable-adjusted relative risk (RR) for stroke mortality grouped according to serum total cholesterol (TC) after adjustment for age, serum albumin, body mass index, hypertension, diabetes, cigarette smoking, and alcohol intake. RR data are shown as black bars for men and white bars for women (from Okamura T, et al. ${ }^{12}$ ). No group has significantly lower or higher RR than the reference group.

women) was approximately three times that in the lowest quintile $(<98 \mathrm{mg} / \mathrm{dl}$ in men and $<106 \mathrm{mg} / \mathrm{dl}$ in women). Similar results were also observed for non-HDLC. However, there was no correlation between the incidence of any subtype of stroke and either LDLC or non-HDLC.

The relationship between serum lipids and cerebral infarction warrants further investigation because the study did not evaluate the effect of serum LDLC or non-HDLC 

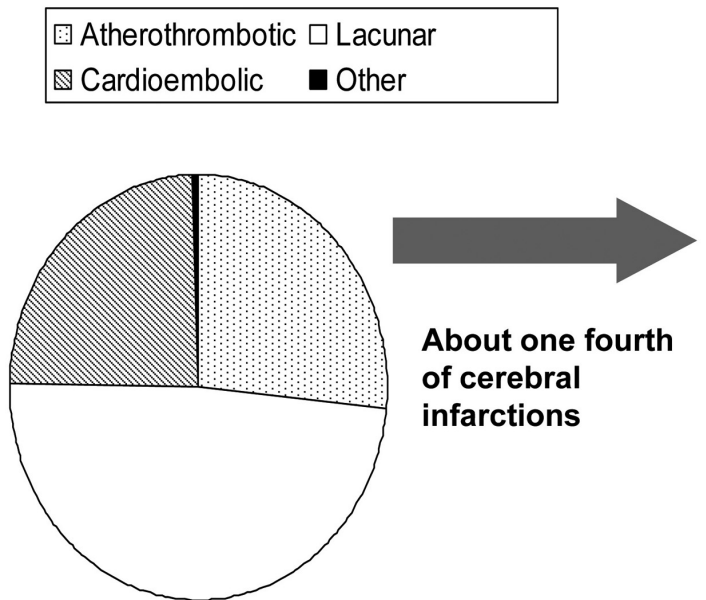

Total number of cerebral infarctions during follow-up: $\mathrm{N}=191$

\section{LDLC and atherothrombotic Infaretion}

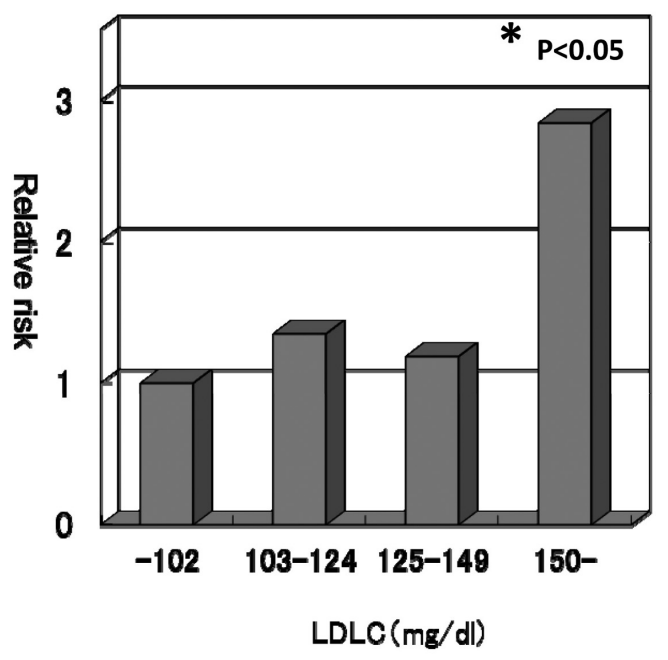

Fig. 3 Low-density lipoprotein cholesterol (LDLC) and atherothrombotic type cerebral infarction in the Hisayama study.

Pie chart (left) showing the proportion of each subtype of cerebral infarction detected during 19 years of follow-up in the Hisayama study. The bar graph (right) shows the relationship between LDLC and relative risk (RR) of atherothrombotic cerebral infarction. Each bar shows RR stratified by LDLC quartiles after adjustment for age, sex, high-density lipoprotein cholesterol, triglycerides, systolic blood pressure, ECG abnormalities, fasting blood glucose, body mass index, current drinking, current smoking, and regular exercise (from Imamura T, et al. ${ }^{15}$ ). $* \mathrm{P}<0.05$ vs. bottom quartile.

on each subtype of cerebral infarction due to the small number of stroke cases, especially for atherothrombotic cerebral infarctions.

\section{The Hisayama study}

A cohort study in the town of Hisayama in Fukuoka Prefecture has been ongoing since 1961 and is the most famous cohort study on cardiovascular disease in Japan. In this study, when stroke or CAD occurs or is suspected, physicians in the study team examine the subject and evaluate his/her detailed clinical information. Furthermore, when a subject dies, an autopsy is performed at the Department of Pathology of Kyushu University. In the reference study, ${ }^{15}$ a total of 2351 residents were followedup for 19 years. Analysis showed that the association between LDLC and the incidence of total stroke, cerebral infarction, or hemorrhagic stroke (subarachnoid hemorrhage and intracerebral hemorrhage) was not significant. However, the risk of atherothrombotic cerebral infarction, which represented about one-fourth of all cerebral infarctions, was increased significantly for the fourth quartile of LDLC compared with the first quartile (Fig. 3). In addition, this is the first study in a Japanese population to show an inverse association between LDLC and cardioembolic cerebral infarction. The only limitation in this cohort study is its small number of participants. However, a sufficient number of stroke events have been observed due to the long follow-up period of the study.

\section{Cohort Studies in Western Populations}

As described above, the majority of cohort studies in Japan failed to demonstrate a positive relationship between hypercholesterolemia and stroke. In contrast to the universally established evidence that hypercholesterolemia is associated with an increased risk of CAD, the effect of hypercholesterolemia on cerebral infarction remains controversial, even in Western populations. For example, a positive association between TC and cerebral infarction was observed in the multiple risk factor intervention trial (MRFIT) in the U.S. ${ }^{22}$ and in the Copenhagen City Heart Study in Europe. ${ }^{23}$ However, the Atherosclerosis Risk in Communities Study (ARIC study) showed that TC was not associated with increased risk of total cerebral infarction, ${ }^{24}$ although hypercholesterolemia was associated with non-lacunar, non-embolic stroke (i.e., atherothrombotic stroke). Similar results were observed in the Hisayama study. ${ }^{15} \mathrm{~A}$ very large meta-analysis of individual data from 61 prospective studies, most of which were car- 


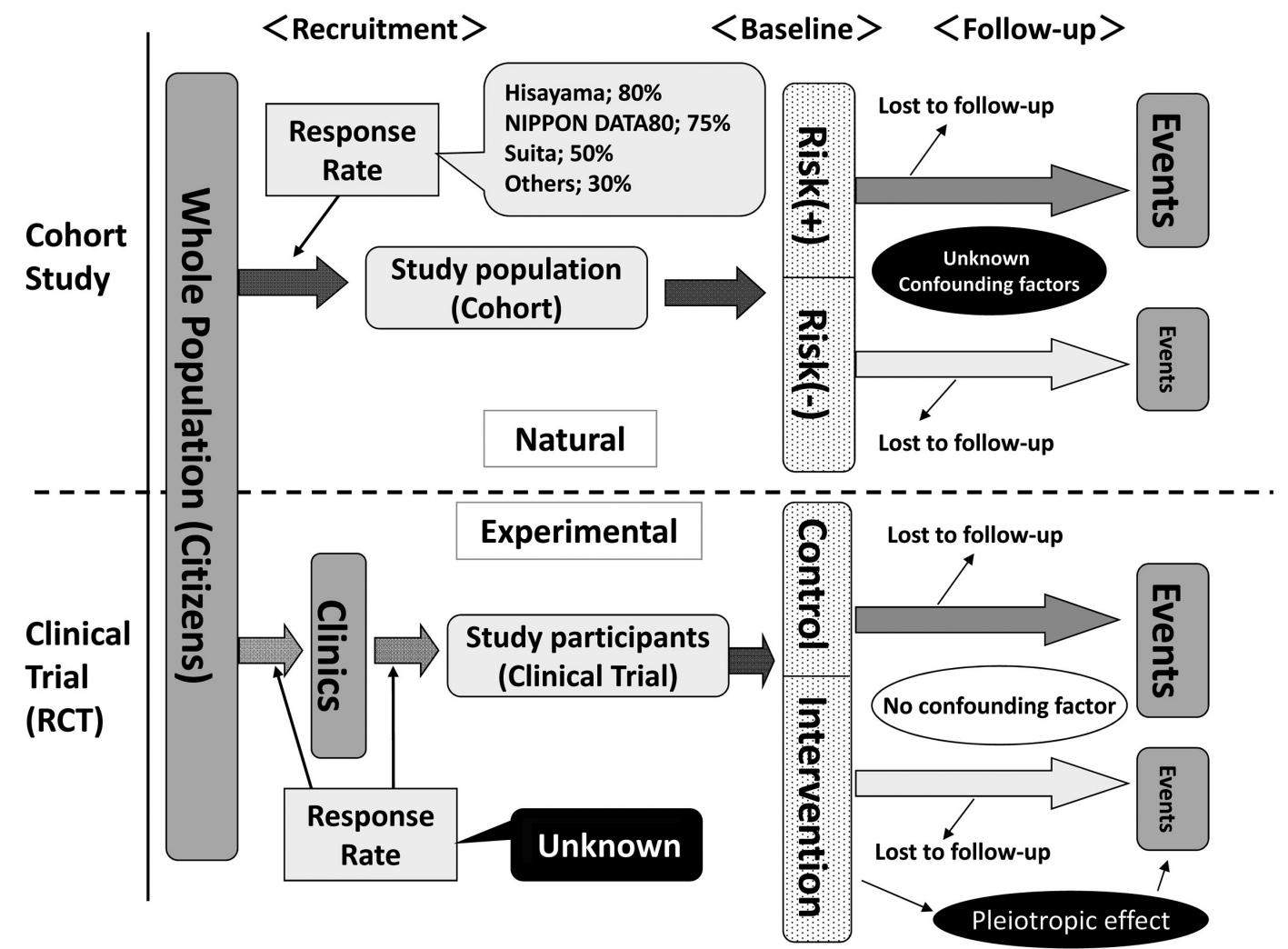

Fig. 4 Putative issues in study design for cohort studies and clinical trials [randomized controlled trials (RCTs)].

In RCTs, there is no information on whether the participants are representative of the parent population. Furthermore, clinical trials may be affected by pleiotropic or off-target effects of each medicine. In contrast, it is possible to accurately calculate the participation rate of the parent population in cohort studies, although theoretically, cohort studies cannot control for unknown confounding factors.

ried out in U.S. and European populations, showed no independent positive association between $\mathrm{TC}$ and ischemic and total stroke mortality. ${ }^{25}$ Consequently, in cohort studies, the relationship between hypercholesterolemia and cerebral infarction may be modified by the proportion of atherothrombotic infarctions in the population surveyed. In a population or country with a low proportion of atherothrombotic cerebral infarctions, the relationship between hypercholesterolemia and cerebral infarction may be difficult to detect. However, from the viewpoint of patients and the general population, hypercholesterolemia should be thought of as a risk factor for stroke because it does seem to affect the risk of some types of stroke.

\section{Randomized Controlled Trials}

Recent randomized controlled trials (RCTs) have shown that statins used as either primary ${ }^{26}$ or secondary prevention $^{27}$ substantially reduced levels of CAD and cerebral infarction. Statin therapy has also been shown to successfully decrease the risk of cerebral infarction or composite outcome of CAD or cerebral infarction in Japanese trials. ${ }^{28,29}$ However, caution is needed when interpreting the results of these clinical trials. First, although there have been numerous clinical trials on statin therapy, the primary endpoint of these studies was CAD, with cerebral infarction usually being the secondary endpoint in the protocols. To our knowledge, only the Stroke Prevention by Aggressive Reduction in Cholesterol Levels (SPARCL) was designed with stroke as the primary endpoint. ${ }^{30}$ Second, statins have well-known pleiotropic effects that prevent cardiovascular disease. These include anti-inflammatory effects, an improvement in vascular endothelial function, and plaque stabilization. This may be a reason why we observed a significant discrepancy between the results of cohort studies and clinical trials. ${ }^{31}$ However, a recent meta-analysis indicated that further reductions in LDLC result in further decreases in the incidence of cerebral infarction with no evidence of any lower threshold. ${ }^{32}$ An ongoing clinical trial to examine whether the addition of ezetimibe to statin therapy improves cardiovascular outcomes compared with statin alone may provide in- 
formation concerning the pleiotropic effects of statins. ${ }^{33}$ Because both RCTs and cohort studies have fundamental limitations, it is important to take the findings from both study designs into account. The RCT design provides no information as to whether the participants are representative of the parent population, whereas this may be clear in cohort studies. In community-based or worksite cohort studies it is also possible to calculate the participation rate of the parent population. To examine weak associations suggested by cohort studies, such as that between hypercholesterolemia and stroke, it is necessary to use caution and prudence when interpreting the results of clinical trials, even those with an RCT design. The putative issues in both types of study design are summarized in Figure 4.

\section{Risk of Low Blood Cholesterol Levels}

Five out of 14 studies in Table 1 observed an inverse relationship between serum TC (or LDLC) and hemorrhagic stroke, mainly intracerebral hemorrhage. ${ }^{11-13,17,21}$ In 1990, a National Heart, Lung, and Blood Institute (NHLBI) Conference was held to discuss the associations between low blood cholesterol and non-coronary mortality. ${ }^{34}$ The conference concluded that most of the inverse associations between cholesterol and non-coronary mortality, such as cancer, could be explained by reverse-causality such as pre-existing disease, unadjusted confounding factors, and socio-economic status. However, this report recommended that further studies should be undertaken on causal mechanisms linking low TC and hemorrhagic stroke. Several hypotheses have been proposed to explain the inverse association between cholesterol and intracerebral hemorrhage. ${ }^{35}$ First, low blood cholesterol may induce angionecrosis, possibly in association with hypertension; however, experimental evidence of this effect is limited. Second, low blood cholesterol may reflect poor nutritional status, which is known to be related to death after onset of stroke, but not to onset per se. The inverse association between cholesterol and hemorrhagic stroke is most commonly observed when stroke mortality is the endpoint in cohort studies. Third, there may be some residual confounding factors. In the majority of clinical trials on statin therapy, it is very rare for an increase in intracerebral hemorrhage to be observed during trials. However, in the SPARCL study that used stroke as the primary endpoint, hemorrhagic stroke was more frequently observed in patients treated with statins, especially in those with a past history of hemorrhagic stroke or hypertension. ${ }^{30}$ Further research is needed in various fields of medical science to validate these hypotheses and also to explain the findings of the SPARCL study.

The Hisayama study ${ }^{15}$ and probably one other study ${ }^{21}$ showed an inverse relationship between blood cholesterol and cardioembolic cerebral infarction. We are unaware of any known mechanisms to explain this relationship. One plausible explanation is that low blood cholesterol alone or low dietary magnesium in combination with low blood cholesterol may increase the risk of atrial fibrillation, ${ }^{36,37}$ the main risk factor for cardioembolic infarction. However, there is little evidence to support this possibility at the present time.

\section{Conclusions and Directions for Future Research}

There have been few cohort studies on the relationship between serum cholesterol levels and cardiovascular disease in Japan. One reason for this is the low incidence in Japan of CAD, which is associated strongly with hypercholesterolemia. As described in this article, the association between hypercholesterolemia and cerebral infraction is weak, making it difficult to perform epidemiologic studies due to the need for large sample sizes to achieve sufficient statistical power.

Furthermore, there are some residual issues to be clarified in the cohort studies in Japan. Some cohort studies in Japan have shown an inverse relationship between HDLC and cerebral infarction or stroke. ${ }^{38,39}$ The Suita study showed a positive relationship between serum triglycerides (TG) and cerebral infarction. ${ }^{40}$ However, none of these studies showed any association between TC (LDLC) and the risk of cerebral infarction. From the viewpoint of the "lipid hypothesis," it is difficult to understand these findings. Because both HDLC and TG are strongly associated with metabolic syndrome and visceral fat accumulation, participants of cohort studies with abnormalities in these lipids may be affected by the new onset of hypertension during follow-up, which may be related to the incidence of stroke. ${ }^{41}$ However, most cohort studies did not evaluate the longitudinal trend for each risk factor after the baseline survey. Accordingly, we need further research to address this concern.

The atherogenic effect of hypercholesterolemia is well established and is based on evidence from numerous epidemiological, pathological, and biological studies. Furthermore, the proportion of atherothrombotic cerebral infarctions may have recently increased in Japan, because this subtype currently accounts for approximately one third of cerebral infarctions in the Japan Standard Stroke Registry Study (JSSRS). ${ }^{42}$ We should formulate a confirmed strategy for lipid management to prevent cerebral infarction. Toward this end, further long-term, prospective research needs to be undertaken to clarify the effect of blood cholesterol levels on stroke.

\section{Acknowledgments}

This research was supported by a Grant-in-Aid from the Ministry of Health, Labor, and Welfare, Health and Labor Sciences Research Grants, Japan (Comprehensive Research on Cardiovascular and Life-Style Related Diseases: H23-Junkankitou [Seishuu]-Ippan-005). 


\section{References}

1. Pekkanen J, Linn S, Heiss G, Suchindran CM, Leon A, Rifkind BM, Tyroler HA: Ten-year mortality from cardiovascular disease in relation to cholesterol level among men with and without preexisting cardiovascular disease. N Engl J Med 1990; 322: 17001707. [Medline] [CrossRef]

2. Conroy RM, Pyörälä K, Fitzgerald AP, Sans S, Menotti A, De Backer G, De Bacquer D, Ducimetière P, Jousilahti P, Keil U, Njølstad I, Oganov RG, Thomsen T, Tunstall-Pedoe H, Tverdal A, Wedel H, Whincup P, Wilhelmsen L, Graham IM: SCORE project group: Estimation of ten-year risk of fatal cardiovascular disease in Europe: the SCORE project. Eur Heart J 2003; 24: 987-1003. [Medline] [CrossRef]

3. Teramoto T, Sasaki J, Ueshima H, Egusa G, Kinoshita M, Shimamoto K, Daida H, Biro S, Hirobe K, Funahashi T, Yokote K, Yokode M: Executive summary of Japan Atherosclerosis Society (JAS) guideline for diagnosis and prevention of atherosclerosis cardiovascular diseases for Japanese. J Atheroscler Thromb 2007; 14: 267-277. [Medline] [CrossRef]

4. Kitamura A, Noda H, Nakamura M, Kiyama M, Okada T, Imano H, Ohira T, Sato S, Yamagishi K, Iso H: Association between non-high-density lipoprotein cholesterol levels and the incidence of coronary heart disease among Japanese: The Circulatory Risk in Communities Study (CIRCS). J Atheroscler Thromb 2011; 18: 454-463. [Medline] [CrossRef]

5. Cui Y, Blumenthal RS, Flaws JA, Whiteman MK, Langenberg P, Bachorik PS, Bush TL: Non-high-density lipoprotein cholesterol level as a predictor of cardiovascular disease mortality. Arch Intern Med 2001; 161: 1413-1419. [Medline] [CrossRef]

6. Liu J, Sempos CT, Donahue RP, Dorn J, Trevisan M, Grundy SM: Non-high-density lipoprotein and very-low-density lipoprotein cholesterol and their risk predictive values in coronary heart disease. Am J Cardiol 2006; 98: 1363-1368. [Medline] [CrossRef]

7. Ueshima H, Sekikawa A, Miura K, Turin TC, Takashima N, Kita Y, Watanabe M, Kadota A, Okuda N, Kadowaki T, Nakamura Y, Okamura T: Cardiovascular disease and risk factors in Asia: a selected review. Circulation 2008; 118: 2702-2709. [Medline] [CrossRef]

8. Kitamura A, Iso H, Naito Y, Iida M, Konishi M, Folsom AR, Sato S, Kiyama M, Nakamura M, Sankai T: High-density lipoprotein cholesterol and premature coronary heart disease in urban Japanese men. Circulation 1994; 89: 2533-2539. [Medline]

9. Nakayama T, Date C, Yokoyama T, Yoshiike N, Yamaguchi M, Tanaka H: A 15.5-year follow-up study of stroke in a Japanese provincial city. The Shibata Study. Stroke 1997; 28: 45-52. [Medline] [CrossRef]

10. Tanizaki Y, Kiyohara Y, Kato I, Iwamoto H, Nakayama K, Shinohara N, Arima H, Tanaka K, Ibayashi S, Fujishima M: Incidence and risk factors for subtypes of cerebral infarction in a general population: the Hisayama study. Stroke 2000; 31: 2616-2622. [Medline] [CrossRef]

11. Okamura T, Kadowaki T, Hayakawa T, Kita Y, Okayama A, Ueshima H: Nippon Data80 Research Group: What cause of mortality can we predict by cholesterol screening in the Japanese general population? J Intern Med 2003; 253: 169-180. [Medline] [CrossRef]

12. Okamura T, Tanaka H, Miyamatsu N, Hayakawa T, Kadowaki T, Kita Y, Nakamura Y, Okayama A, Ueshima H, NIPPON DATA80 Research Group: The relationship between serum total cholesterol and all-cause or cause-specific mortality in a 17.3-year study of a Japanese cohort. Atherosclerosis 2007; 190: 216-223. [Medline] [CrossRef]

13. Cui R, Iso H, Toyoshima H, Date C, Yamamoto A, Kikuchi S, Kondo T, Watanabe Y, Koizumi A, Inaba Y, Tamakoshi A, JACC Study Group: Serum total cholesterol levels and risk of mortal- ity from stroke and coronary heart disease in Japanese: the JACC study. Atherosclerosis 2007; 194: 415-420. [Medline] [CrossRef]

14. Okamura T, Kokubo Y, Watanabe M, Higashiyama A, Miyamoto Y, Yoshimasa Y, Okayama A: Low-density lipoprotein cholesterol and non-high-density lipoprotein cholesterol and the incidence of cardiovascular disease in an urban Japanese cohort study: The Suita study. Atherosclerosis 2009; 203: 587-592. [Medline] [CrossRef]

15. Imamura T, Doi Y, Arima H, Yonemoto K, Hata J, Kubo M, Tanizaki Y, Ibayashi S, Iida M, Kiyohara Y: LDL cholesterol and the development of stroke subtypes and coronary heart disease in a general Japanese population: the Hisayama study. Stroke 2009; 40: 382-388. [Medline] [CrossRef]

16. Ishikawa S, Matsumoto M, Kayaba K, Gotoh T, Nago N, Tsutsumi A, Kajii E; Jichi Medical School (JMS) Cohort Study Group: Risk charts illustrating the 10-year risk of stroke among residents of Japanese rural communities: the JMS Cohort Study. J Epidemiol 2009; 19: 101-106. [Medline] [CrossRef]

17. Noda H, Iso H, Irie F, Sairenchi T, Ohtaka E, Doi M, Izumi Y, Ohta H: Low-density lipoprotein cholesterol concentrations and death due to intraparenchymal hemorrhage: the Ibaraki Prefectural Health Study. Circulation 2009; 119: 2136-2145. [Medline] [CrossRef]

18. Li Q, Morikawa Y, Sakurai M, Nakamura K, Miura K, Ishizaki M, Kido T, Naruse Y, Suwazono Y, Nakagawa H: Occupational class and incidence rates of cardiovascular events in middle aged men in Japan. Ind Health 2010; 48: 324-330. [Medline] [CrossRef]

19. Tanabe N, Iso H, Okada K, Nakamura Y, Harada A, Ohashi Y, Ando T, Ueshima H, Japan Arteriosclerosis Longitudinal Study Group: Serum total and non-high-density lipoprotein cholesterol and the risk prediction of cardiovascular events - the JALS-ECC. Circ J 2010; 74: 1346-1356. [Medline] [CrossRef]

20. Nago N, Ishikawa S, Goto T, Kayaba K: Low cholesterol is associated with mortality from stroke, heart disease, and cancer: the Jichi Medical School Cohort Study. J Epidemiol 2011; 21: 67-74. [Medline] [CrossRef]

21. Tsuji H: Low serum cholesterol level and increased ischemic stroke mortality. Arch Intern Med 2011; 171: 1121-1123. [Medline] [CrossRef]

22. Iso H, Jacobs DR Jr, Wentworth D, Neaton JD, Cohen JD: Serum cholesterol levels and six-year mortality from stroke in 350,977 men screened for the multiple risk factor intervention trial. N Engl J Med 1989; 320: 904-910. [Medline] [CrossRef]

23. Lindenstrøm E, Boysen G, Nyboe J: Influence of total cholesterol, high-density lipoprotein cholesterol, and triglycerides on risk of cerebrovascular disease: the Copenhagen City Heart Study. BMJ 1994; 309: 11-15. [Medline] [CrossRef]

24. Kurth T, Everett BM, Buring JE, Kase CS, Ridker PM, Gaziano JM: Lipid levels and the risk of ischemic stroke in women. Neurology 2007; 68: 556-562. [Medline] [CrossRef]

25. Prospective Studies Collaboration: Lewington S, Whitlock G, Clarke R, Sherliker P, Emberson J, Halsey J, Qizilbash N, Peto $\mathrm{R}$, Collins R: Blood cholesterol and vascular mortality by age, sex, and blood pressure: a meta-analysis of individual data from 61 prospective studies with 55,000 vascular deaths. Lancet 2007; 370: 1829-1839. [Medline] [CrossRef]

26. Mills EJ, Rachlis B, Wu P, Devereaux PJ, Arora P, Perri D: Primary prevention of cardiovascular mortality and events with statin treatments: a network meta-analysis involving more than 65,000 patients. J Am Coll Cardiol 2008; 52: 1769-1781. [Medline] [CrossRef]

27. Vergouwen MD, de Haan RJ, Vermeulen M, Roos YB: Statin treatment and the occurrence of hemorrhagic stroke in patients with a history of cerebrovascular disease. Stroke 2008; 39: 497502. [Medline] [CrossRef]

28. Sasaki J, Arakawa K, Iwashita M, Matsushita Y, Kono S, Kyushu 
Lipid Intervention Study (KLIS) Group: Reduction in serum total cholesterol and risks of coronary events and cerebral infarction in Japanese men: the Kyushu Lipid Intervention Study. Circ J 2003; 67: 473-478. [Medline] [CrossRef]

29. Nakamura H, Arakawa K, Itakura H, Kitabatake A, Goto Y, Toyota T, Nakaya N, Nishimoto S, Muranaka M, Yamamoto A, Mizuno K, Ohashi Y, MEGA Study Group: Primary prevention of cardiovascular disease with pravastatin in Japan (MEGA Study): a prospective randomised controlled trial. Lancet 2006; 368: 1155-1163. [Medline] [CrossRef]

30. Amarenco P, Bogousslavsky J, Callahan A III, Goldstein LB, Hennerici M, Rudolph AE, Sillesen H, Simunovic L, Szarek M, Welch KM, Zivin JA, Stroke Prevention by Aggressive Reduction in Cholesterol Levels (SPARCL) Investigators: High-dose atorvastatin after stroke or transient ischemic attack. N Engl J Med 2006; 355: 549-559. [Medline] [CrossRef]

31. Uchiyama S, Nakaya N, Mizuno K, Ohashi Y, Tajima N, Kushiro T, Teramoto T, Nakamura H, MEGA Study Group: Risk factors for stroke and lipid-lowering effect of pravastatin on the risk of stroke in Japanese patients with hypercholesterolemia: analysis of data from the MEGA Study, a large randomized controlled trial. J Neurol Sci 2009; 284: 72-76. [Medline] [CrossRef]

32. Cholesterol Treatment Trialists' (CTT) Collaboration: Baigent C, Blackwell L, Emberson J, Holland LE, Reith C, Bhala N, Peto R, Barnes EH, Keech A, Simes J, Collins R: Efficacy and safety of more intensive lowering of LDL cholesterol: a meta-analysis of data from 170,000 participants in 26 randomised trials. Lancet 2010; 376: 1670-1681. [Medline]

33. Cannon CP, Giugliano RP, Blazing MA, Harrington RA, Peterson JL, Sisk CM, Strony J, Musliner TA, McCabe CH, Veltri E, Braunwald E, Califf RM, IMPROVE-IT Investigators: Rationale and design of IMPROVE-IT (IMProved Reduction of Outcomes: Vytorin Efficacy International Trial): comparison of ezetimibe/ simvastatin versus simvastatin monotherapy on cardiovascular outcomes in patients with acute coronary syndromes. Am Heart J 2008; 156: 826-832. [Medline] [CrossRef]

34. Jacobs D, Blackburn H, Higgins M, Reed D, Iso H, McMillan G, Neaton J, Nelson J, Potter J, Rifkind B, Rossouw J, Shekekke R,
Yusuf S: for Participants in the Conference on Low Cholesterol: Mortality Associations: Report of the conference on low blood cholesterol: mortality associations. Circulation 1992; 86: 10461060. [Medline]

35. Okamura T: Low blood cholesterol and intraparenchymal hemorrhage in cohort studies. J Atheroscler Thromb 2010; 17: 312-314. [Medline] [CrossRef]

36. Psaty BM, Manolio TA, Kuller LH, Kronmal RA, Cushman M, Fried LP, White R, Furberg CD, Rautaharju PM: Incidence of and risk factors for atrial fibrillation in older adults. Circulation 1997; 96: 2455-2461. [Medline]

37. Nielsen FH, Milne DB, Klevay LM, Gallagher S, Johnson L: Dietary magnesium deficiency induces heart rhythm changes, impairs glucose tolerance, and decreases serum cholesterol in post menopausal women. J Am Coll Nutr 2007; 26: 121-132. [Medline]

38. Soyama Y, Miura K, Morikawa Y, Nishijo M, Nakanishi Y, Naruse Y, Kagamimori S, Nakagawa H: High-density lipoprotein cholesterol and risk of stroke in Japanese men and women: The Oyabe Study. Stroke 2003; 34: 863-839. [Medline] [CrossRef]

39. Okamura T, Hayakawa T, Kadowaki T, Kita Y, Okayama A, Ueshima H, NIPPON DATA90 Research Group: The inverse relationship between serum high-density lipoprotein cholesterol level and all-cause mortality in a 9.6-year follow-up study in the Japanese general population. Atherosclerosis 2006; 184: 143-150. [Medline] [CrossRef]

40. Okamura T, Kokubo Y, Watanabe M, Higashiyama A, Ono Y, Miyamoto Y, Yoshimasa Y, Okayama A: Triglycerides and nonhigh-density lipoprotein cholesterol and the incidence of cardiovascular disease in an urban Japanese cohort: the Suita study. Atherosclerosis 2010; 209: 290-294. [Medline] [CrossRef]

41. Laaksonen DE, Niskanen L, Nyyssönen K, Lakka TA, Laukkanen JA, Salonen JT: Dyslipidaemia as a predictor of hypertension in middle-aged men. Eur Heart J 2008; 29: 2561-2568. [Medline] [CrossRef]

42. Toyoda K, Okada Y, Kobayashi S: Early recurrence of ischemic stroke in Japanese patients: the Japan standard stroke registry study. Cerebrovasc Dis 2007; 24: 289-295. [Medline] [CrossRef] 